\title{
A smarter knowledge commons for smart learning
}

Penelope J. Lister(10

\author{
Correspondence: penelope.lister. \\ 16@um.edu.mt \\ Department of Leadership for \\ Learning and Innovation, Faculty of \\ Education, University of Malta, \\ Msida, UK
}

\begin{abstract}
This paper takes the form of a discussion relating to a smarter knowledge commons, having come about due to implications arising from research into the development of a pragmatic pedagogical 'guide to learning' for smart learning environments. The paper does not discuss any research findings (which have not yet been established), but rather is about attempting to discover through examination of early adopter use cases the underlying challenge for smart learning design in relation to the delivery of personalised geo-spatially relevant knowledge. Solutions for the mapping and delivery of the knowledge web are tentatively suggested, making use of an existing meta-property framework, the Open Graph.

Smart learning environments focus on learning in geo-spatially relevant learning locations, with tutors or learners engaged in tasks that may frequently require the searching and selecting of knowledge content to contribute to learning or in the further production of new digital knowledge content. This has led to considerations regarding where and how knowledge content is obtained, provided, produced or shared, and this paper examines issues related to the producing, searching and finding of knowledge content in these learning contexts. Practical examples are provided to illustrate how digital knowledge content plays a pivotal role in learning design and learner interactions taking place in smart learning, both for the content of learning and as part of the process for learning.

Emphasis is on open access smart learning in relation to connected and collaborative pedagogical approaches. Considering the future development and pedagogies of open-access smart learning environments, we must ask how the knowledge commons, an integral part of this learning, can become 'smarter' for learning and teaching.
\end{abstract}

Keywords: Smart learning, Pedagogy, Connectivism, Data society, Knowledge commons, Linked open data, Facebook, Open graph, Schema, RDF

\section{Introduction}

In the context of the author's research into a digital pedagogy for smart learning environments, learning activities in smart learning are considered to be contextualised in the networked learning activities of Beetham (2012:45). Beetham highlights practical ways of describing types of connected learning applicable to learning 'online', using illustrative terms to think about what learners do in relation to relevant connected learning interactions. In summary these are discovery, collecting and gathering, problem solving, developing techniques, collaborating and sharing ideas. The aim of the author is to develop this concept further for smart learning environments, building and combining

(c) The Author(s). 2018 Open Access This article is distributed under the terms of the Creative Commons Attribution 4.0 International License (http://creativecommons.org/licenses/by/4.0/), which permits unrestricted use, distribution, and reproduction in any medium, provided you give appropriate credit to the original author(s) and the source, provide a link to the Creative Commons license, and indicate if changes were made. 
ideas around interactions and activities that may apply to the hybrid (Gros 2016b, Floridi 2015:43), connectivist (Downes 2006; Siemens 2005) style activities perhaps evident in smart learning. However, this paper is not concerned with discussing the development and research of the pedagogy of smart learning but rather with the digital knowledge that forms a key part of the learning content and of the process for learning in smart learning environments.

Interest has arisen as a practical consequence of the development of smart learning journeys that form part of the research into smart learning pedagogy. In the course of this work it has become apparent that the Creative and Knowledge Commons ${ }^{1,2}$ form significant elements of these developments. Creative Commons is used for intellectual property licensing of original knowledge content created by tutor experts for these smart learning experiences, and often for the content that is sourced from pre-existing digital knowledge materials, and hence would be 'open access'. These knowledge sources play a pivotal role in the learning design of smart learning. It may also be that as smart learning communities develop in the future, any resulting learner generated content (Pérez-Mateo et al. 2011) might also (very likely) be licensed under Creative Commons, becoming part of the geo-tagged open access knowledge commons for a given location.

Utilising existing online knowledge sources in learning design is not new for either tutor or learner. For example, a tutor selects existing digital content to 'push' toward their learners, as set reading or recommended links, or that learners are required to find and review relevant knowledge sources to contribute to their understanding of a topic. It is worth noting that technologically speaking this is known as 'pull technol$\mathrm{ogy}^{3}$, as it is client-side instigated, that is, it is initiated by a human agent, the tutor or student, as they pull the content to themselves by their own interactions. However, in smart learning or related literature, considerable discussion is dominated by concepts surrounding the non-human agent intelligent delivery of content (Siemens 2006:43, Hwang, 2014:5,8), in other words, how to 'push' content smartly to the user, using intelligent non-human agency such as machine-learned smart algorithms. Technologically speaking, this is known as 'push technology'4. That is, to activate server-side pushed content, relevant to prior learner or tutor interactions and prior searching behaviours, but not instigated by the client (the tutor or student) directly. This content uses analytics data from a variety of sources to 'machine' activate selections of relevant content, and 'pushes' it toward the tutor or learner, without them having to have instigated the action or the selections themselves. Server-side pushed content might be provided similarly to how e-commerce or social media platforms already implement such targeted content suggestions (for example Amazon product suggestions, or Facebook targeted ads). To confuse things further, those in the educational community, including technology enhanced learning, tend to use these terms in opposite contexts to the technological definitions (see endnotes [3] and [4]), for example in Gros: "A fundamental shift is needed towards a more personalised, social, open, dynamic, emergent and knowledge-pull model for learning, as opposed to the one-size-fits-all, centralised, static, top-down and knowledge-push models of traditional learning solutions (Chatti et al., 2010, p.67)" (Gros 2016a:2). So the educator sees 'knowledge-push' models in terms of prescribed learning content (e.g. set reading), while 'knowledge-pull' models are seen as personalised and emergent. Perhaps one challenge of smart learning is to become a boundary 
object between technology and technology enhanced learning in discourse, terminology and understanding.

\section{Defining smart learning}

It is useful to attempt to define smart learning for the purposes of discussion in this paper as definitions vary within the smart learning research community. Much of the relevant research concerns learning within smart cities, or smart learning that is conceptualised and determined by technology, infrastructure and the production and analysis of large datasets (Nikolov et al. 2016; Liu et al. 2017a; Giannakos et al. 2016). In contrast to this are publications concerned with citizens, either as inhabitants of smart cities or as learners within ad-hoc smart learning environments (Giovanella et al. 2016; Thomas et al. 2016; Mullagh et al. 2014). While no single standardised way of defining smart learning yet exists, some commonalities arise in these discourses, such as personalised learning experiences enhanced by intelligent non-human agents, just-in-time delivery of information, the significance of geospatial relevance for content delivery selection and notions about socio-temporal glocality (Meyrowitz 2005) in the persistent collaborative learning interactions taking place.

Smart learning can often be happening without any formal tutor, or even any conscious acknowledgement of it (Buchem and Pérez-Sanagustín 2013). Citizens go about their daily lives perpetually interacting with information and technology to develop knowledge and skills relevant to what is happening at that moment. Just-in-time delivery of knowledge (for example S Schiltz et al. 2007) is seen as a core expectation of these interactions. Hwang's 2014 interpretation regards smart learning environments as "technology-supported learning environments that make adaptations [...] in the right places and at the right time $[\ldots]$ analyzing their learning behaviors, performance and the online and real-world contexts in which they are situated (Hwang et al. 2008)", (2014:5). Liu et al. offer the succinct descriptive definition of "learning to learn, learning to do and learning to self-realization" (Liu et al. 2017b) placing emphasis on the learner and the overall purpose of learning in smart learning environments.

\section{Smart learning contextual discourse}

Literature relevant to open access smart learning is perhaps predominantly based in a 'connected-learner' (Siemens 2005, McLaughlin and Lee 2009:339) Connectivist or Social Constructivist epistemology, with general conceptual groupings of location-based, mobile and networked learning discourses. Emphasis in this paper is on the role and sources of knowledge content in a 'connectivist inspired' networked smart learning, and while focus may not be placed on pedagogical factors specifically, a pedagogical perspective offers helpful understanding for interpretation.

Debate relevant to smart learning goes as far back as 2006, when George Siemens, the founder of Connectivism, was predicting what smart learning environments would be capable of and asking how we might develop pedagogical understanding for them: "(w)hat happens when the knowledge we require is presented to us without having to consciously seek it (artificial intelligence)?", (Siemens 2006, p. 56), and "perhaps even our notion of design is worth rethinking - do we design learning? Or do we design environments in which motivated learners can acquire what they need" (Siemens 2006, p. 119). 
Siemens makes many allusions to what we might now term a smart knowledge commons, and outlines the difference between old style archiving with fixed taxonomies, and new style information 'streams'. "We do not yet have the tool that permits 'stepping into the stream.' Library catalogues and encyclopedias attempt to put knowledge into a reservoir - to categorize and structure it in a manner that makes sense. This is rooted in traditional conceptions of knowing: ontology and epistemology", (ibid, p54). It is Siemens' 'tool to step into the stream' that is of particular relevance to smart learning, and that this paper is attempting to examine.

Clearly, the established notion of location being significant in smart learning must be acknowledged, the case for which has already been made adequately elsewhere (for example Gros 2016a). Gros emphasises "the need for adaptation and personalisation, taking into account the places where learning occurs. In smart learning the location in real time is important data required by systems in order to adapt the content and situation to the learner", (Gros 2016a:2). This 'hybridization' Gros describes further as "composed of several technologies that have the interconnection and integration of the physical and digital worlds in common", listing augmented reality, the Internet of things, wearable-technology devices and the quantified self (Gros 2016b:5). Therefore Gros is emphasing how smart technologies enable the refinement of content delivery for learning, adapted by location and real time to personalize this delivery on a just-in-time basis in a connected 'sociospatiotemporal' (Marton and Booth 1997:82) context. Gros outlines this hybrid ubiquity of smart learning, quoting Sharples (2014) to describe the seamlessness of experiences as a "continuity of learning across a combination of locations, times, technologies and social settings", (Gros 2016a).

This paper concerns how we provide personalised smarter knowledge delivery for this seamless continuity of learning. Factors of faceted search and retrieval of knowledge such as geo-tagging, educational level, topic, or via particular institution author, preconfigured selection or smart choice offerings might all be considered as aims of smart knowledge delivery. Knowledge would be accessed via real-time location recognition (described in the later section on smart learning journeys), or in any scenario benefitting from metadata taxonomy content descriptors, set in the context of ubiquitious computing and pervasive connectivity prevelant today.

\section{Networks and information}

We can see the importance of a smarter and more personalised (adaptive and findable) knowledge delivery corresponding to location in real time are considered significant aspects of smart learning environments, and form part of the context of a smart learning pedagogy. Therefore, examining relationships between networks and information will be further explored.

The findability (Morville 2005, Siemens 2006, p 56) of digital knowledge content in personalized ways such as level of learning, location, topic choice and relevance for a specific geo-tagged and augmented point of interest poses multiple challenges. Ensuring a 'level playing field' delivery of information search results, either as individual sources or hyperlink access to whole repositories of knowledge, appears increasingly difficult in the age of search engine optimization, paid search ranking and 'gaming the search crawlers' (Clark and Rossmann 2017). Kop drew attention to this in 2012, highlighting search results returned by Google: "Google accounts for $72.15 \%$ of all 
searches in the USA (Experian Hitwise, 2010) and 90\% in the European Union (White \& Campbell, 2010), which makes Google's behavior and its integrity in relation to the access it provides to information crucial to networked learning". Friesen and Lowe (2012) also raised concerns surrounding the commercialization of these algorithms, indicating that personalization may only revolve around commercial interest and purposes, which may work at odds with citizen approaches and needs for learning and personal knowledge development. Bias in choices offered being paid for via sponsored advertising blur the lines of what is most relevant, useful and of high quality with what is simply commercially promoted content. The skills of navigating these murky waters add to the complexity for the development of critical information and digital literacies.

Advice as of 2018 available from Facebook ${ }^{5}$ for content dissemination optimisation or Feedly ${ }^{6}$ for how to optimise non-human agent discoverability and human agent findability of content demonstrate techniques that may either be interpreted as gaming the system or as optimising content and meta data consistency for search result accuracy and findability. These methods can be employed not only by ubiquitous Google search algorithms or large commercial or national organisations but also by individuals who wish to promote their content so as to gain a potential advantage in search result rankings. Once on this pathway, the 'Matthew Effect' (Barabasi and Bonabeau 2003, quoting 'noted sociologist Robert Merton') can exponentially increase this potential advantage of node and hub connectivity and increased visibility for any piece of connected digital content. This concern becomes compelling when considered in a context of connectivist (learning) networks, (Carreño 2014; AlDahdouh et al. 2015), in the continuously advancing capabilities of deep learning intelligent algorithms that control information delivery in search results. Arguably, results weighting according to (primarily) commercial interest may not be the best way for knowledge access to be managed (Kop 2012, p6). Yet, this is how knowledge content and information are currently (still) sorted and delivered.

Kop's work additionally raises the issue and importance of serendipity (also Siemens 2006, p56), in that "(a)lgorithm-based search engines and recommenders are very good at aiding in directive searches, but they are not so good at replicating serendipity; the chance of finding a gem of information, unrelated to a focused search, more as a by-product, that stimulates our creativity and thinking to arrive at a particular insight" (2012).

Authenticity of content is becoming a challenge, the trust of the content itself, in terms of authorship and revisioning. Katz and Gandel, in 'The Tower, the Cloud, and Posterity' (Katz and Gandel 2008), have argued that the challenges of authenticity and custodianship in what they term 'The Fourth Archivy' of digital knowledge are potentially unsolvable. They highlight issues related to authenticated content, digital versioning and even the challenge of technology being able to read the data at all (for example, 3 or 5 in. floppy discs are un-accessible, or older CD and DVD corrupted data discs).

\section{Knowledge content in smart learning}

To understand the role of knowledge content in smart learning, this section provides examples of simple use cases consisting of 'smart learning journeys'. These are briefly outlined, together with a description of a typical user-learner experience. 


\section{Examples of real world smart learning}

So as to envisage smart learning in geo-spatially relevant places, three case study 'smart learning journeys' are briefly outlined to illustrate what happens in this kind of smart learning environment, and how learning might take place. Two existing journeys are part of ongoing doctoral research by the author, and attempt to shed light on the process as well as the content of learning in real world smart environments, helping to develop a pragmatic digital pedagogy for this kind of learning.

Both the existing London and Maltese smart learning journeys described below use two smartphone apps, Aurasma (now rebranded as HP Reveal) triggers digital knowledge content augmentations created by the author together with the tutor, and Edmodo is used for learner interactive collaboration. Google Maps is also used to provide a route and supporting information. A third hypothetical smart learning journey is offered for 'future thinking' contrast, imagining use of Google Lens ${ }^{7}$ technology, now available on the Google Pixel phone and other Android devices ${ }^{8}$, that may be indicative of standard features in up-coming smartphones. This smart learning journey imaginary is modeled on the existing journeys, to help conceptualise where smart learning might be in the near future.

The user-learner interactive experience in all three examples would consist of using a smartphone to access augmented content via geo-spatial trigger points marked along a real world journey, using the camera viewfinder. Pointing the camera at each location trigger point would access learning content, tasks and perhaps collaborative interactions relevant to that location or feature. Original digital knowledge content created by the tutor, or pre-existing webpage knowledge, are accessed by the learners at these locations. Learning tasks might include finding other relevant knowledge content as part of knowledge construction, critical awareness and literacy skills learning. Learners might further be required to produce their own content, therefore becoming 'student-as-producer' (Higher Education Academy 2012). This type of 'learner-generated content' (Pérez-Mateo et al. 2011) would additionally describe community knowledge construction in relation to smart learning for local citizen initiatives or learning experiences such as city gardens, citizen heritage trails, or 'the city as archive' (Hetherington 2013).

It is important to reiterate here that this paper is not concerned with research data or findings, but has come about due to the practical challenge of knowledge resource delivery for the 'smart learning journeys' described here and being investigated as part of doctoral research. This research is ongoing, and as yet no findings are available. These smart learning journeys attempt to establish early adopter use cases to act as smart learning indicators and serve to highlight practical challenges that contribute to a smart learning pedagogy of such activities and experiences. One of the key evident challenges is how to provide personalised faceted search and retrieval of knowledge.

\section{Literary London learning journey}

Collaboration between the author and the course leader of BA English Literature at London Metropolitan University resulted in the 'Literary London' smart learning journey (see Fig. 1), located in and around St Paul's cathedral in the City of London, UK. Consisting of approximately twelve augmented locations plus other points of interest along the way, content was developed and sourced for each digitally augmented trigger 


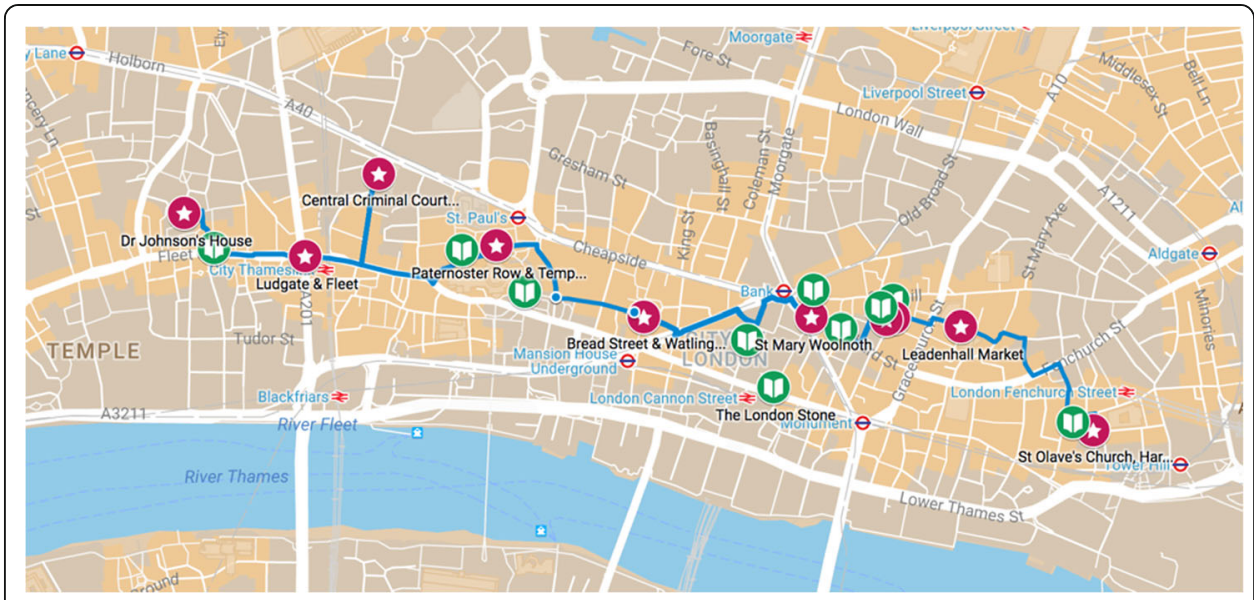

Fig. 1 The Literary London Smart Learning Journey route in Google Maps (http://bit.ly/literary-london-map)

that included webpage links, original webpage content, videos and image galleries. The journey was around two and a half kilometres. Students were requested to participate in the journey as part of formative exercises to learn about developing literary tours based on locations.

\section{Maltese democracy learning journey}

The 'Maltese Democracy' smart learning journey (see Fig. 2) has been developed as a collaboration between the author and the module leader for elective modules pertaining to Technology Enhanced Learning, for BEd and MA Education students at University of

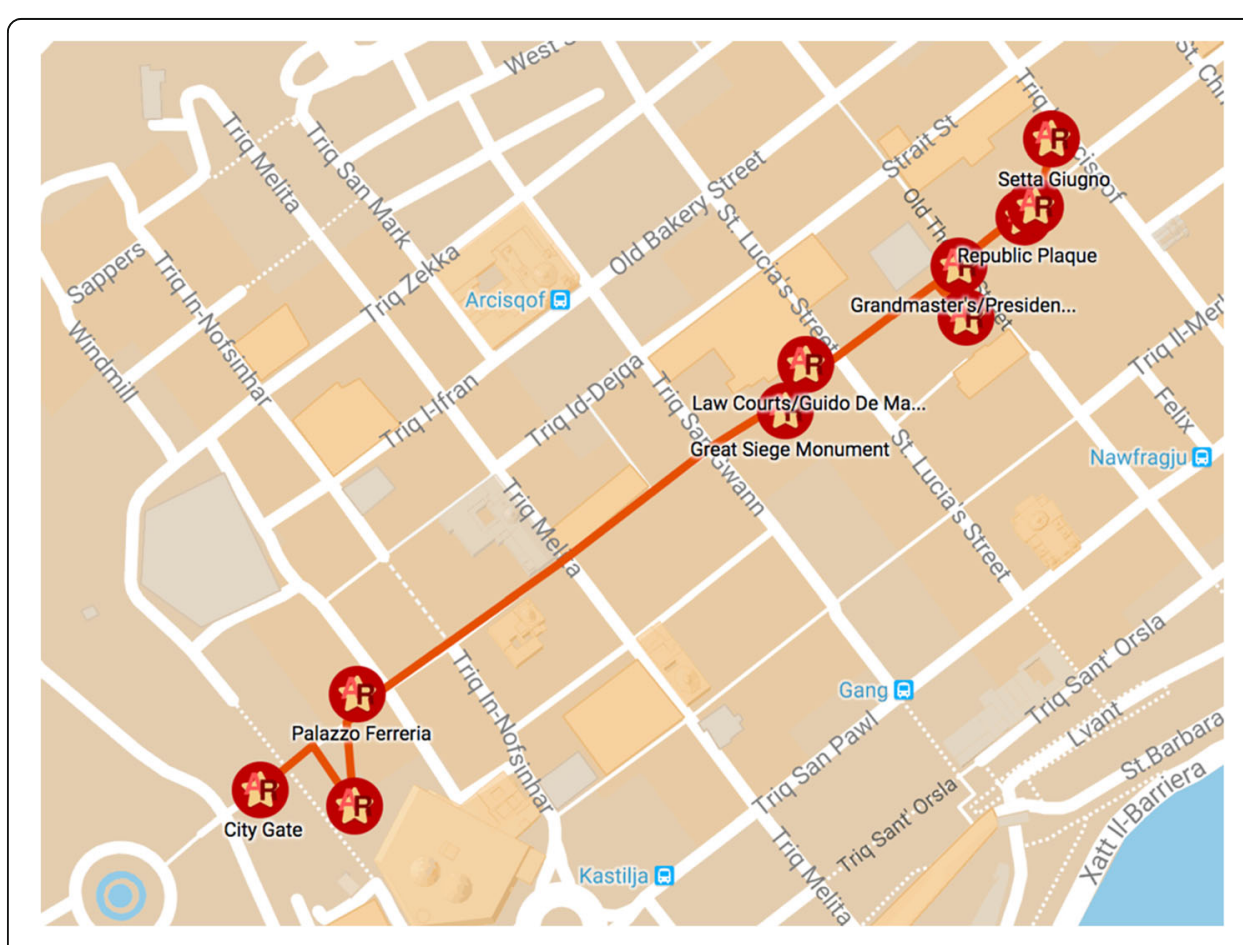

Fig. 2 The Maltese Democracy Smart Learning Journey route in Google Maps (http://bit.ly/maltesedemocracy-map) 
Malta. This journey was located along Republic Street in Valletta, going from City Gate down to St George's Square. This was a shorter journey of around six hundred metres. Knowledge content was developed principally using open access commons such as Wikipedia, Wikimedia and Flickr Commons, with some additional copyrighted content under granted permissions. Students were requested to participate in the journey as part of formative exercises to learn about developing smart learning journeys.

\section{'Google Lens' imaginary learning journey}

In an imaginary future smart learning journey utilizing functionality similar to that which Google Lens already offers, the user-learner experience becomes more seamless, and potentially a lot more 'smart'. In this future journey, the user is able to point their camera at buildings or features and, via Google Lens type functions, is able to source knowledge content intelligently. This might be achieved by having 'learning preferences' as additional personal Google identity configurations, or by using a dedicated app with similar settings, or by using social media identities and preferences, or a mixture of these (e.g. perhaps similar to Shibboleth ${ }^{9}$ ). Topics of interest, level of learning, formal or informal type of learning and so forth might be pre-configured so that by accessing geo-tagged knowledge, the user-learner is offered suitable knowledge choices and interactions. Examples already exist such as Wikimedia Maps projects ${ }^{10}$, showing how content with geo-tag coordinates can be called up smartly using any smartphone or laptop GPS location function as reference. 'DBPedia Places ${ }^{11}$ ' is an example of a smartphone app that calls up Linked Open Data ${ }^{12}$ Wikipedia content, with geo-tagged properties relevant to real time location.

For a 'Google Lens imaginary journey' to become possible, knowledge networks must be mapped intelligently so that non-human agents can search and find relevant knowledge content much more accurately. Additionally, content creators must be able to add metadata to their original content so as to include it in these smart knowledge networks. Ideally, the tutor could pre-select their 'bespoke' content as prescribed learning content and attach it to the geospatial trigger, enabling students to benefit from human expert guidance, as well as intelligent non-human content choices offered.

\section{Potential solutions to a smarter knowledge commons}

In developing these smart learning journeys, 'smarter' connectivity to knowledge content (both push and pull) is immediately relevant. Mechanisms that may offer the potential for achieving a smarter knowledge commons will be briefly examined by looking at discourses from a variety of disciplines. The Internet of Things (IoT), Semantic Web, Information Science and Learning Analytics combine to develop tentative conclusions. Focus here is predominantly on findability and potential pedagogical consistency in a context of authenticated quality assurance. Technology is considered within these aims and parameters.

If we consider the different disciplines related to smart knowledge network content delivery, then boundary object interdisciplinary factors for connecting information (Morville 2014) can be outlined. These might be summarized as geo-spatial reference; authenticity and quality; topic; educational level; interoperability between platforms, devices and things; and findability. These might be further conceptualized as metadata 
and functional criteria or desirability. Note that for purposes of this discussion, metadata properties are considered as html non-human readable 'tag' information about the content (that is, data about the data), and serve to sort and categorise the source, type and potentially quality and authenticity of knowledge information.

Potential metadata properties for smart learning:

1. Geo-spatial reference (Geo-tag coordinates)

2. Authenticity, quality (including author)

3. Topic (subject area)

4. Educational level

Additional functionally desirable criteria for smart learning:

A. Interoperability between platforms, devices and things

B. Enhanced and intelligent human and non-human findability

These meta-properties adopt a position of the desirability for a smart knowledge network system to achieve the following: to geo-tag each knowledge network 'node', to evidence authenticity and hence quality, to have a meta property for subject topic or discipline, thereby enabling enhanced and more efficient search and find capability, and to indicate an established standard of educational learning level such as the European Qualifications Framework (EQF), for example. These might be said to be pedagogical taxonomy values for a smart knowledge network. Ideally, these pedagogical meta-tag properties would be simple to implement and 'human readable, that is, understandable and usable by any author to add at time of publishing or post publish date, for any piece of digital knowledge content. Perhaps this is a pragmatic interpretation of implementing Henning's 'closing the loop of human learning and machine support' (Henning 2018, p284).

Some debate examining ways of mapping the knowledge networks concerns methods using complex and detailed meta-data Resource Description Framework attribute (RDFa) systems based upon Schema structured data ${ }^{13}$. For example, Badita (2016) makes a case for an Open Graph standard for education, describing a granular detail level of mapping content, similar to how Open Education Resources Schema ${ }^{14}$ works. A challenge of these methods is that they can be cumbersome to implement, perhaps indicated by Schema itself often not being implemented at all (Pospelova 2014). Other detailed meta-data systems such as the Dublin Core exist, though information on uptake and findability effectiveness of Dublin Core is conflicting (Trustlove 2014; Si 2015). Using Schema, an html inline 'element/attribute' system (micro-data), means that html code needs to be added to pages of content in the html 'body', potentially a laborious process (though alternate methods such as JSON-LD or JavaScript can be used to implement Schema micro-data). Whilst Schema can be useful for search engine 'rich snippet' content, and for recording micro-interactions to track user behaviour and goal conversion for specific content attributes, arguably, it is not necessary for findability and smart delivery.

By far the most successful and fastest growing content RDF metadata system is the Open Graph ${ }^{15}$, Facebook's meta-property specification, available under the Open Web 
Foundation Agreement ${ }^{16}$. Open Graph meta-properties are added to the head of the html code, not the inline body elements. Dynamic data calls can be used to populate meta-properties for multiple pages of websites, providing unique properties for each web page, and the system is fast and effective to implement at scale. The Web Technologies Surveys website quotes for year 2017 that $41.2 \%$ of Internet websites now use RDFa of some type, and of that, 38.4\% are using the Open Graph: "Open Graph is used by $93.3 \%$ of all the websites who use RDFa", (Web Technologys Surveys, 2018). This pervasive uptake is for numerous reasons but for purposes of this discussion, it may be summarized as 'Perceived Use, Perceived Ease of Use' (Davis 1989), perceived usefulness for connectivity and search result visibility, and ease of use for implementation. In this sense, it may offer the fastest and most effective way of mapping the knowledge web, simply by adding a few (fewer than ten, as indicated previously) pedagogical meta-properties to the existing main open graph ('og') meta-property set. Additionally, the Open Graph achieves the two desirable functional factors for connected knowledge, interoperability and findability. It is already realistically interoperable by virtue of its ubiquity, easily implemented and contributes to enhancing findability of content nodes at granular level (unique identifier rather than repository).

The Open Graph uses linked data Unique Resource Identifier (URI) principles to identify publisher and admin owner(s) via the Facebook Developer Application Programming Interface $\left(\mathrm{API}^{17}\right)$, and these could be modified to incorporate institution and author URI's, thereby evidencing quality and authenticity. A Unique Resource Location (URL) identifies each specific piece of digital content, or additionally adopt a Universally Unique Identifier 'UUID', permitting perhaps more efficient searching in any 'non-relational' data context. The Open Graph's 'Geopoint' geo-tag coordinate and location meta-properties allow for search by location to a precise level. By adding additional tags for topic (partially catered for in Open Graph 'Article' properties but could be defined specifically) and educational level (EQF, K-12 etc), network knowledge content nodes could be found and delivered more accurately, and searched via a Representational State Transfer (RESTful ${ }^{18}$ ) API as described in Gyrard et al. (2016). This would mean they were independent of any single app or platform, only dependent on a simple RDF and API system. While space here does not permit more detailed examination for how topic, institution, author and educational level could be added as additional Open Graph properties, it is not complex to imagine that this could be done.

Gyrard et al. (2016) describe semantic web structures connecting knowledge with a smart Internet of things: “...semantic web languages such as RDF [...] to explicitly describe the data, and [...] provide a basis to later infer high level abstractions from sensor data. Connecting unified semantics enriched IoT data to the knowledge bases available on the web has a huge potential to build smart systems". They outline 'Linked Open Services', making specific reference to connecting semantic web technologies via RESTful API: "(s)ervices can be implemented according to RESTful principles or with the help of semantic web technologies to enhance interoperability (e.g., OWLS). This approach could be extended for designing a set of interoperable services", (2016, p5). Zouaq et al describe a linked data for education model that also outlines some similar approaches using URI and RDF to connect data intelligently. They also stress the importance of a simple system: "( $t$ )hanks to the simplicity of these principles, LD represents an elegant framework for modelling and querying data at a global scale", (Zouaq et al. 2017, p 348). 
In an ideal world, an API would exist such as outlined above, and a learner app or platform, for example Blackboard LMS, Moodle or Edmodo, could be configured via an open access plugin to use a faceted search mechanism that makes use of Open Graph metadata descriptors and Google Lens or similar technology to access smart choice knowledge nodes via a camera viewfinder - providing augmented digital content access. These contextual knowledge choices could be 'faceted' by learner level, topic, etc., and pre-selections made by a tutor previously if used in more formal circumstances. (NB, the author is in process of writing a paper that would investigate this concept at much greater depth.)

It is important to acknowledge that there is considerable work and debate on mapping the knowledge networks within a variety of disciplines (information science, semantic web, computer science and so forth). However, this author asserts that debate has been going on for some time, yet statistics speak for themselves in the case of a preferred RDF system for website content owners. If the knowledge communities were to embrace the most popular system, then the challenge of mapping and connecting the knowledge commons, and perhaps with it the pay-walled knowledge web, could become a reality quite quickly. This is certainly a usable approach, avoiding the echo chambers of technology insider discussions that fail to see the wider applied purposes (Hillerbrand 2016), and acknowledging the simplicity of the system required.

\section{Some challenges}

The question of how smart an intelligent content delivery system should or needs to be to play a reliable, consistent and trustworthy part in the learning society is at the heart of the challenges faced by any smart knowledge network. Kop reminds us that trust is involved in permitting artificial intelligence to provide knowledge, asking: "could we ever trust a machine, even though it is tweaked by humans, to find really useful (her emphasis) information for us?", (2012, p4).

In order to foster critical skills in information search and selection it might seem counter productive to make information retrieval easier. However, taking into account the rapidly evolving depth and challenges of artificial intelligence currently taking place (Hof 2013; Rahwan and Cebrian 2018) begins to hint that digital literacy as we see it now will change, becoming that which Siemens described when he stated " $(t)$ echnology will be increasingly depended upon to mediate the bulk of our current knowledge seeking behavior. We spend much of our time seeking and trying to locate what we need - findability is still a primary knowledge behavior. Once knowledge is more tightly integrated in contexts of use, we can shift more attention to the act of application. We need to move beyond finding and evaluating relevance, to use and application", (2006, p56).

Though some literature in the field of IoT is relevant to this paper for discourse surrounding relationships between IoT, semantic web and the web of knowledge (see also digital asset management and artificial intelligence discourse, for example, Rossi 2017), in the context of this paper, IoT is itself not directly relevant, and associated personal privacy becomes less problematic. For example, no sensors are required for technology in existing apps such as Google Lens, only Wi-Fi, GPS and smartphone location are required. No data tracking or data exchange is involved in personally identifiable ways, unless at app or platform (internal) level and a user is logged in, thereby ensuring 
learner privacy. This might be understood in the way that Google search engines work without a user being logged in. The search history is recorded by the search engine itself, but not attributable to the user unless they are logged in. Personalised smart knowledge delivery could potentially therefore be achieved in data secure ways, because search data recorded by and for the search algorithm are not personally identifiable at search engine level, only from within an app or platform that the user chooses to be logged in to (like Facebook targeted ads or Amazon suggestions). Space here does not permit a more in depth discussion of these technical aspects, as the main focus here is on ways to achieve the mapping of knowledge nodes (or objects, i.e. webpages) for smart delivery, in terms of search choices and selections, via utilisation of an enhanced Open Graph metadata system.

\section{Conclusions}

Working with proprietary platform frameworks may not be the ideal context to establishing educational findability metadata protocols, as literature indicates it is fraught with problems (Van Dijck 2013, Srnicek 2016). However, Google and Microsoft currently control the largest search engines, and the Facebook Open Graph is the most used RDF content discoverability framework on the World Wide Web. It may be that by building a simple, elegant and reliable structured data system of authenticated knowledge content using an existing and widely used framework, and by making it accessible via RESTful API, we are levelling the playing field to access content more accurately, and more fairly, by all. Perhaps most especially for the open knowledge and data already present on the Internet in the context of socio-spatio-temporal open access smart learning, this is a satisfactory goal in itself.

\section{Endnotes}

${ }^{1}$ The Creative Commons. https://creativecommons.org/. "When we share, everybody wins".

${ }^{2}$ Knowledge Commons Wikipedia definition: "information, data, and content that is collectively owned and managed by a community of users, particularly over the Internet". Also "(a) main principle of the knowledge commons is that the traditional "copyright" is being replaced by 'copyleft". However, webpage knowledge often has no obvious copyright licence of any kind, and grey areas persist.

${ }^{3}$ Definitions of 'pull technology', Wikipedia: https://en.wikipedia.org/wiki/Pull_technology; PC Magazine: https://www.pcmag.com/encyclopedia/term/49948/pull-technology.

${ }^{4}$ Definitions of 'push technology', Wikipedia: https://en.wikipedia.org/wiki/Push_technology; Techopedia: https://www.techopedia.com/definition/5732/push-technology.

${ }^{5}$ Facebook Newsfeed Publisher Guidelines https://www.facebook.com/help/publisher/ newsfeedguidelines.

${ }^{6}$ Feedly feed optimization with metadata and https://blog.feedly.com/10-ways-to-optimize-your-feed-for-feedly/.

${ }^{7}$ Wikipedia explanation of Google Lens https://en.wikipedia.org/wiki/Google_Lens.

${ }^{8}$ The Verge explain Google Lens and device availability https://www.theverge.com/ 2018/5/11/17339450/google-lens-android-camera-app-how-to (accessed 16-05-18).

${ }^{9}$ Shibboleth Sign in, how it works: https://www.shibboleth.net/index/basic/.

${ }^{10}$ Wikimedia Maps example for Valetta, Malta http://bit.ly/wikimedia-valletta-osm.

${ }^{11}$ DBPedia http://wiki.dbpedia.org/; DBPedia Places app http://wiki.dbpedia.org/projects/dbpedia-places. 
${ }^{12}$ Wikipedia defines Linked Data as 'a term used to describe a recommended best practice for exposing, sharing, and connecting pieces of data, information, and knowledge on the Semantic Web...' http://linkeddata.org/ and https://en.wikipedia.org/wiki/ Open_data.

${ }^{13}$ Schema.org http://schema.org/docs/about.html.

${ }^{14}$ Open Educational Resources Schema http://oerschema.org/docs/.

${ }^{15}$ The Open Graph http://ogp.me/

${ }^{16}$ Open Web Foundation http://www.openwebfoundation.org/legal/the-0-9-agreements$\% 2 \mathrm{D}$-necessary-claims

${ }^{17}$ API definition: https://en.wikipedia.org/wiki/Application_programming_interface

${ }^{18}$ RESTful definition: https://en.wikipedia.org/wiki/Representational_state_transfer

\begin{abstract}
Abbreviations
API: Application Programming Interface; EQF: European Qualifications Framework; GPS: Global Positioning System; JSON-LD: JSON programming language with linked data; K-12: The American secondary school system; LD: Linked data; MWD: Mobile Web Devices; OWL: Web Ontology Languages; RDF: Resource description Framework; RDFa includes 'attributes'; RESTful: Representational state transfer; URI: Unique resource identifier; URL: Unique resource location; UUID: Universally unique identifier
\end{abstract}

\title{
Funding
}

The author is a self funded doctoral candidate at University of Malta, Faculty of Education, Department of Leadership for Learning and Innovation, and receives no additional external funding.

\section{Authors' contributions}

This is a single author work. The author read and approved the final manuscript

\section{Authors' information}

I confirm that this manuscript has not been published elsewhere and is not under consideration by another journal. Penelope J Lister. MA, MSc, MBCS, FHEA. PhD Candidate, University of Malta, Faculty of Education, Department of Leadership for Learning and Innovation. Former Senior Lecturer at London Metropolitan University, UK. Email: penelope.lister.16@um.edu.mt.

I have spent ten years teaching multimedia and digital media from extended degree to post graduate level at London Metropolitan University, UK. My knowledge areas are website development and best practice, rich media and social media for SME's, NGO's and similar. More recently I became involved in Technology Enhanced Learning, supporting continuing professional development for academics in the uses and best practice for technology in learning and teaching. My special interests are the Semantic Web, RSS and content syndication, and digital copyright. My PhD is in smart pedagogies for geo spatially related learning, investigating how smart learning can adopt pedagogical approaches in smart content delivery contexts.

\section{Competing interests}

The author declares that he/she has no competing interests.

\section{Publisher's Note}

Springer Nature remains neutral with regard to jurisdictional claims in published maps and institutional affiliations.

Received: 22 June 2018 Accepted: 25 July 2018

Published online: 13 August 2018

\section{References}

A AlDahdouh, A Osório, S Caires, Understanding knowledge network, learning and connectivism. Int J Instr Technol Dist Learn 12(10), 3-23 (2015)

F Badita, Changing the world of Publishing - Creating a (sic) Open Graph Standard. Blogpost. (2016) Available from: https://medium.com/@baditaflorin/changing-the-world-of-publishing-creating-a-open-graph-standard7fd3191038c6. Accessed 5 May 2018

AL Barabasi, E Bonabeau, Scale Free Networks. Sci Am 288(5), 60 (2003)

A White \& M Campbell. (2010, December 1) Google probed by European Union over search results, online ads, Bloomberg anywhere. Bloomberg. Retrieved March 20, 2012, from, http://bloom.bg/eNwX50.

H Beetham, Designing for active learning in technology-rich contexts. Beetham, H., \& Sharpe, R. (Eds.), Rethinking Pedagogy for a Digital Age: Designing for 21st Century Learning (2nd) (Pp 49-63). New York and London. Routledge; Taylor \& Francis (2012)

I Buchem, \& M Pérez-Sanagustín, Personal learning environments in smart cities: Current approaches and future scenarios. eLearning Papers no. 35 (2013)

( Carreño, Theory of Connectivity as an Emergent Solution to Innovative Learning Strategies. Am J Educ Res, 2, 2: 107-116. (2014). Retrieved from http://www.aupress.ca/index.php/books/120235 
JA Clark, D Rossmann, The open SESMO (Search Engine \& Social Media Optimization) project: Linked and structured data for library subscription databases to enable web-scale discovery in search engines. J Web Librariansh 11(3-4), 172-193 (2017). https://doi.org/10.1080/19322909.2017.1378148

FD Davis, Perceived Usefulness, Perceived Ease of Use, and User Acceptance of Information Technology. MIS Quarterly 13(3), 319-340 (1989)

J Dijck, The Culture of Connectivity, a Critical History of Social Media (Oxford University Press, Oxford, UK \& New York, 2013)

S Downes, Learning networks and connective knowledge. Instructional Technology Forum: Paper 92 (2006). Available from https://www.downes.ca/cgi-bin/page.cgi?post=36031. Accessed 5 May 2018

L Floridi (ed.), The Onlife manifesto, Being Human in a Hyperconnected Era (Springer, Cham, Heidelberg, New York, Dordrecht, London, 2015). https://doi.org/10.1007/978-3-319-04093-6

N Friesen, S Lowe, The questionable promise of social media for education: Connective learning and the commercial imperative. J Comput Assist Learn 28, 183-194 (2012)

M Sharples, A Adams, R Ferguson, M Gaved, P McAndrew, B Rienties, M Weller, D Whitelock, Innovating Pedagogy. Open University Innovation Report 3 (The Open University, Milton Keynes, 2014)

MA Chatti, MR Agustiawan, M Jarke, M Specht, Toward a Personal Learning Environment Framework. Int. J. Virtual. Pers. Learn. Environ. 1(4), 66-85 (2010).

MN Giannakos, DG Sampson, L Kidziński, Introduction to smart learning analytics: Foundations and developments in video-based learning. Smart Learn Environ 3, 12 (2016). https://doi.org/10.1186/s40561-016-0034-2

C Giovanella, A Martens, I Zualkernan, in Grand Challenge Problems in Technology-Enhanced Learning II: MOOCs and Beyond, SpringerBriefs in education, ed. by J Eberle et al.. Grand challenge problem 1: People centered smart 'cities' through Smart City learning (2016). https://doi.org/10.1007/978-3-319-12562-6_2

B Gros, The Design of Smart Educational Environments. Smart Learning Environments (Springer Open Access, 2016a)

B Gros, in The Future of Ubiquitous Learning. Lecture Notes in Educational Technology, ed. by B Gros, Kinshuk \& Maina, M. The dialogue between emerging pedagogies and emerging technologies (Springer, Heidelberg, New York, Dordrecht, London, 2016b)

A Gyrard, P Patel, AP Sheth, M Serrano, Building the web of knowledge with smart loT applications. IEEE Intell Syst 31(5), 83-88 (2016) https://corescholar.libraries.wright.edu/knoesis/1123

PA Henning, in Knowledge Management in Digital Change, New Findings and Practical Cases, ed. by K North, R Maier, O Haas. Learning 4.0 (Springer International Publishing AG, Switzerland, 2018), pp. 277-290

K Hetherington, Rhythm and noise: The city, memory and the archive. The Sociological Review 61(S1), 17-33 (2013). https://doi.org/10.1111/1467-954X.12051

Higher Education Academy, Impact Case Study: Student as Producer: Embedding Student Engagement in Learning and Teaching and Research. HEA collaboration with the University of Lincoln (2012) Retrieved from https://www. heacademy.ac.uk/system/files/downloads/case_study_university_of_lincoln.pdf

E Hillerbrand, in Semantic Web, ed. by M Workman. Semantic web and business: Reaching a tipping point? (Springer International Publishing, Switzerland, 2016). https://doi.org/10.1007/978-3-319-16658-2_11

RD Hof, Deep learning with massive amounts of computational power, machines can now recognize objects and translate speech in real time. Artificial intelligence is finally getting smart. [blog post]. MIT Review. Retrieved from https://www.technologyreview.com/s/513696/deep-learning/ (2013), Accessed 3 June 18

RN Katz, PB Gandel, in The Tower and the Cloud: Higher Education in the Age of Cloud Computing, ed. by R Katz. The tower, the cloud, and posterity (Educause, USA, 2008)

R Kop, The unexpected connection: Serendipity and human mediation in networked learning. Educ Technol Soc 15(2), 2-11 (2012)

D Liu, R Huang, M Wosinski, Characteristics and Framework of Smart Learning. Smart Learning in Smart Cities, Lecture Notes in Educational Technology (Springer Nature, Singapore Pte Ltd. 2017a)

D Liu, R Huang, M Wosinski, in Smart Learning in Smart Cities. Lecture Notes in Educational Technology. Future Trends in Smart Learning: Chinese Perspective (Springer, Singapore, 2017b)

F Marton, S Booth, Learning and Awareness (Lawrence Erlbaum Associates, Mahwah, 1997)

C McLaughlin, M Lee, in Handbook of research on social software and developing community ontologies, ed. by S Hatzipanagos, S Warburton. Pedagogical responses to social software in universities (Information Science Reference, IGl Global, Hershey and London, 2009), pp. 335-356

J Meyrowitz, in The Global and the Local in Mobile Communication, ed. by K Nyíri. The rise of Glocality, new senses of place and identity in the Global Village (Passagen Verlag, Vienna, 2005)

P Morville, Ambient Findability (O'Reilly Media, USA, 2005)

P Morville, Intertwingled: Information Changes Everything (Ann Arbour, USA, 2014)

L Mullagh, L Blair, N Dunn, Beyond the 'smart' City: Reflecting human values in the urban environment. (SMART 2014: The Third International Conference on SMART Systems, Devices and Technologies. UK. 2014)

R Nikolov, E Shoikova, M Krumova, E Kovatcheva, V Dimitrov, A Shikalanov, Learning in a Smart City environment. J Commun Comput 13(2016), 338-350 (2016)

M Pérez-Mateo, M Maina, FM, Guitert \& M Romero, Learner generated content: Quality criteria in online collaborative learning. In European Journal of Open, Distance and E- Learning-EURODL. Special Themed Issue on Creativity and Open Educational Resources Semantic Studios. (2011)

P Pospelova, Schema markup in university websites [blog post]. Deleted Agency (2014). Accessible at http://www. deleteagency.com/news/schema-markup-in-university-websites. Accessed 28 May 2018.

I Rahwan, \& M Cebrian, Machine behavior needs to be an academic discipline: Why should studying Al behavior be restricted to those who make Al?. Nautilus. Accessible at http://nautil.us/issue/58/self/machine-behavior-needs-tobe-an-academic-discipline (2018). Accessed 29 May 2018.

B Rossi. How Al and metadata are taking the hard work out of content discovery. (2017) Retrieved from https:/www. information-age.com/ai-metadata-taking-hard-work-content-discovery-123464651/ Accessed 20 July 2018

M Schiltz, F Truyen, H Coppens, Cutting the trees of knowledge: Social software, information architecture and their epistemic consequences. Thesis eleven: a new journal working at the crossroads of socialism and scholarship 89, 94-114 (2007) 
S Si, What happened to Dublin Core as an SEO factor?. SEO Hacker. (2015) Accessible at https://seo-hacker.com/ happened-dublin-core-seo-factor/. Accessed 29 May 2018.

G Siemens, "Connectivism: Learning as network-creation", ElearnSpace (2005) Available from: http://www.elearnspace. org/Articles/networks.htm. Accessed 22 Apr 2018.

G Siemens, Knowing Knowledge. ElearnSpace (2006) Available from http://www.elearnspace.org/KnowingKnowledge_ LowRes.pdf. Accessed 10 June 2018

GJ Hwang, CC Tsai, SJH Yang, Criteria, strategies and research issues of context-aware ubiquitous learning. Educ. Technol. Society 11(2), 81-91 (2008).

N Srnicek, Platform Capitalism (Polity, Malden, MA, USA \& Cambridge UK, 2016)

$\checkmark$ Thomas, D Wang, L Mullagh, N Dunn, Where's Wally? In search of citizen perspectives on the Smart City. Sustainability 2016(8), 207 (2016)

R Trustlove, Dublin Core in 2014: Should I really care about it?. Woorank (2014) Accessible at https://www.woorank. com/en/blog/dublin-core-in-2014. Accessed 29 May 2018

A Zouaq, J Jovanović, S Joksimović \& D Gašević, Linked data for learning analytics: Potentials and challenges. In Lang, C., Siemens, G., Wise, A., \& Gašević, D. (Eds), Handbook of Learning Analytics (1st Ed) (pp 347-355). Society for Learning Analytics Research (SoLAR) (2017)

Submit your manuscript to a SpringerOpen ${ }^{0}$ journal and benefit from:

- Convenient online submission

- Rigorous peer review

Open access: articles freely available online

High visibility within the field

- Retaining the copyright to your article

Submit your next manuscript at $\boldsymbol{\nabla}$ springeropen.com 